\title{
Subcellular adaptation of the human diaphragm in chronic obstructive pulmonary disease
}

\author{
M. Orozco-Levi*, J. Gea*, J.L. Lloreta*, M. Félez*, J. Minguella+, S. Serrano*, J.M. Broquetas*
}

Subcellular adaptation of the human diaphragm in chronic obstructive pulmonary disease. M. Orozco-Levi, J. Gea, J.L. Lloreta, M. Félez, J. Minguella, S. Serrano, J.M. Broquetas. (C) ERS Journals Ltd 1999.

ABSTRACT: Pulmonary hyperinflation impairs the function of the diaphragm in patients with chronic obstructive pulmonary disease (COPD). However, it has been recently demonstrated that the muscle can counterbalance this deleterious effect, remodelling its structure (i.e. changing the proportion of different types of fibres). The aim of this study was to investigate whether the functional impairment present in COPD patients can be associated with structural subcellular changes of the diaphragm.

Twenty individuals $(60 \pm 9$ yrs, 11 COPD patients and 9 subjects with normal spirometry) undergoing thoracotomy were included. Nutritional status and respiratory function were evaluated prior to surgery. Then, small samples of the costal diaphragm were obtained and processed for electron microscopy analysis.

COPD patients showed a mean forced expiratory volume in one second (FEV1) of $60 \pm 9 \%$ predicted, a higher concentration of mitochondria $\left(n_{m i t}\right)$ in their diaphragm than controls $\left(0.62 \pm 0.16\right.$ versus $0.46 \pm 0.16$ mitochondrial transections $(\mathrm{mt}) \cdot \mu \mathrm{m}^{-2}$, $\mathbf{p}<\mathbf{0 . 0 5})$. On the other hand, subjects with air trapping (residual volume $(\mathrm{RV}) /$ total lung capacity (TLC) $>37 \%$ ) disclosed not only a higher $n_{\text {mit }}(0.63 \pm 0.17$ versus $\left.0.43 \pm 0.07 \mathrm{mt} \cdot \mu \mathrm{m}^{-2}, \mathrm{p}<0.05\right)$ but shorter sarcomeres $\left(L_{\mathrm{sar}}\right)$ than subjects without this functional abnormality $(2.08 \pm 0.16$ to $2.27 \pm 0.15 \mu \mathrm{m}, \mathrm{p}<0.05)$. Glycogen stores were similar in COPD and controls. The severity of airways obstruction (i.e. FEV1) was associated with $\mathrm{n}_{\mathrm{mit}}(\mathrm{r}=-\mathbf{0 . 5 5 5}, \mathrm{p}=\mathbf{0 . 0 1})$, while the amount of air trapping (i.e. $\left.\mathrm{RV} / \mathrm{TLC}\right)$ was found to correlate with both $\mathrm{n}_{\text {mit }}(\mathrm{r}=0.631, \mathrm{p}=0.005)$ and $L_{\mathrm{sar}}(\mathrm{r}=-\mathbf{0 . 5 2 6}, \mathrm{p}<0.05)$. Finally, maximal inspiratory pressure $(P I, m a x)$ inversely correlated with $n_{\text {mit }}(r-0.547$, $\mathbf{p}=\mathbf{0 . 0 1}$ ).

In conclusion, impairment in lung function occurring in patients with chronic obstructive pulmonary disease is associated with subcellular changes in their diaphragm, namely a shortening in the length of sarcomeres and an increase in the concentration of mitochondria. These changes form a part of muscle remodelling, probably contributing to a better functional muscle behaviour. Eur Respir J 1999; 13: 371-378.
*Servei de Pneumologia, 'Servei de Patologia, ${ }^{+}$Servei de Cirurgia Toràcica and Unitat de Recerca Respiratòria i Ambiental, Hospital del Mar - I.M.I.M., Universitat Pompeu Fabra, Universitat Autònoma de Barcelona, Barcelona, Catalonia, Spain.

\section{Correspondence: J. Gea}

Servei de Pneumologia

Hospital del Mar - IMIM

c/ Doctor Aiguader 80

E-08003 Barcelona

Spain

Fax: 34932213237

Keywords: Chronic obstructive pulmonary disease

hyperinflation

mitochondria

respiratory muscles

sarcomeres

Received: December 91997

Accepted after revision September 241998

Supported by grants BIOMED PL 963406 , FIS 92/0314 and IMIM 1642380. Preliminary results presented at the Annual Meeting of the American Thoracic Society, Seattle (WA), 1995.
Chronic obstructive pulmonary disease (COPD) is a respiratory condition mainly characterized by persistent airflow limitation [1]. It affects $>5 \%$ of the general population [2], is a cause of permanent disability and constitutes one of the leading and increasing causes of death in developed countries [3].

The function of the diaphragm, the main respiratory muscle, can be impaired in patients with COPD owing to both airways obstruction and pulmonary hyperinflation (air trapping) [4-6]. However, it has been demonstrated that this deleterious effect can be partially counterbalanced by the muscle [7]. TАмАOKI [8] found that fibres were hypertrophic in the diaphragm of guinea-pigs with elastaseinduced emphysema. Recently, Levine et al. [9] have demonstrated that patients with severe COPD show a higher percentage of type I fibres in their diaphragm than subjects with normal lung function or mild COPD. These and other changes could be considered adaptive [10-16], contributing to a better functional behaviour of the muscle against respiratory loads. However, other authors have described structural changes, such as atrophy of respiratory muscles [17-19], that do not appear to be so advantageous. Different factors, such as malnutrition and a persistent increase in the mechanical impedance of the respiratory system have been involved in this atrophy. Surprisingly, there are little data concerning the diaphragm at a subcellular level in patients with respiratory diseases. This study was carried out to investigate whether or not the functional impairment present in COPD can be associated with changes in the contractile and energetic systems of the muscle: specifically, with modifications in the length of sarcomeres and density of mitochondria and glycogen stores.

\section{Methods}

Study design and population

This was a cross-sectional study prospectively carried out over a 4 yr period (1991-1995). Subjects were 
progressively included from patients undergoing thoracotomy for a localized lung neoplasm. Individuals suffering from bronchial asthma, severe undernourishment, chronic respiratory failure, chronic metabolic diseases, previous abdominal or thoracic surgery, paraneoplastic syndromes, or those receiving chemotherapy, steroids or other drugs known to modify muscle structure were excluded. Twenty male subjects $(60 \pm 9$ (mean \pm SD) yrs) were finally included. Eleven had COPD (forced expiratory volume in one second (FEV1)/forced vital capacity $(\mathrm{FVC})<70 \%$ ) and the rest disclosed normal spirometric values. All were sedentary individuals and their daily physical activities were similar. The study was approved by the Research Committee on Human Investigation at the authors' institution, and informed written consent was obtained after the purposes and potential risks of the investigation were fully explained and understood by each patient.

Protocol. First day: when informed consent was obtained, patients performed conventional pulmonary function tests and their nutritional status was assessed. Second day: respiratory muscle function was evaluated. Third day: biopsies from costal diaphragm were taken at the beginning of thoracotomy, $24 \mathrm{~h}$ after the functional evaluation. Samples were subsequently processed.

\section{Pulmonary function tests}

Forced spirometry was performed (Datospir 92; Sibel, Barcelona, Spain) and inspiratory capacity, inspiratory thoracic gas volume (ITGV; or functional residual capacity (FRC)) and the transfer factor of the lung for carbon monoxide (TL,CO, single-breath method) (Masterlab; Jaeger, Würzburg, Germany) were measured in each patient. Reference values were those for a Mediterranean population $[20,21]$. Blood samples were obtained from the radial artery and analysed for arterial oxygen tension $\left(\mathrm{Pa}_{\mathrm{a}} \mathrm{O}_{2}\right)$, arterial carbon dioxide tension $\left(\mathrm{Pa}_{\mathrm{a}} \mathrm{CO}_{2}\right)$ and $\mathrm{pH}$, using standard polarographic techniques (ABL 330; Radiometer, Copenhagen, Denmark).

\section{Respiratory muscle function}

This was assessed through transdiaphragmatic pressure $(P \mathrm{di})$ and inspiratory pressure measured at the mouth. The former was obtained using the oesophageal and gastric balloon technique [22]. The balloon catheters were connected to pressure transducers (Transpac II; Abbott, Chicago, IL, USA) and the signals registered using a multichannel recorder (Sensormedics R-611, Anaheim, CA, USA). Calibrations were performed at the beginning and end of each study. $P$ di was determined both during quiet breathing and a maximal inspiratory manoeuvre from FRC (maximal $P \mathrm{di}$ $(P$ di,max $))$. The sniff technique was chosen for the latter because it appears to be more reproducible and easily performable by COPD patients [23]. Ventilatory pattern was also recorded, since subjects were breathing through a low-resistance two-way valve (Hans Rudolph; Kansas City, MO, USA), connected to a pneumotachometer (Screenmate; Jaeger). As a result, the tension-time index of the diaphragm (Ttdi) was also calculated as:

$$
T_{t \mathrm{di}}=(P \mathrm{di} / P \mathrm{di}, \max ) \times(t \mathrm{I} / / \mathrm{tot})
$$

where $t$ I represents the inspiratory time and $t$ tot the duration of the total breathing cycle ([24]. The maximal inspiratory pressure $(P I, \max )$ measured at the mouth was obtained using a manometer with a mouthpiece that could be occluded (Sibelmed, Sibel). Reference values were those published by WILSON et al. [25].

\section{Nutritional assessment}

Nutritional status was evaluated using both anthropometric and biochemical parameters. The former included weight $(\mathrm{kg})$, body mass index $\left(\mathrm{BMI}=\right.$ weight $/$ height $\left.^{2}\right)$, and the percentage of ideal body weight $(\% \mathrm{IBW}=$ (actual weight/ideal weight) $\times 100)[26]$. Blood analysis included serum cholesterol, triglycerides, total proteins, albumin, globulins and prothrombin consumption time.

\section{Structural analysis of the diaphragm}

Light microscopy. Biopsies from the diaphragm $(\sim 0.5$ $\mathrm{cm} \times 0.5 \mathrm{~cm} \times 0.5 \mathrm{~cm}$ in size) were obtained during thoracic surgery. Samples were taken $2 \mathrm{~cm}$ from the costodiaphragmatic angle, below the middle axilar line. Each biopsy was divided into two parts. One was immediately plunged into isopentane (cooled over liquid nitrogen), and stored at $-70^{\circ} \mathrm{C}$. For histochemical procedures, each block was positioned on a cryostat holder roughly transverse to the muscle fibre axis. Consecutive sections were then obtained inclining the holder by $5^{\circ}$; the section with the smallest cross-sectional area (CSA) was chosen [27, 28]. Fibre diameters and CSA were measured using a semiautomatic system (Videoplan-II, Zeiss, Kontron Electronics, Eching, Germany). At least 100 fibres were measured in each case. Using previous studies as a reference, diameters between 40 and $80 \mu \mathrm{m}$ were considered normal [18]. Type I and II fibres were identified with adenosine triphosphate (ATPase) stains at different pHs [29].

Electron microscopy. Samples of the diaphragm were also processed for electron microscopy (EM) according to standard methods (Tissue Processor E9200, BioRad, Boston, MA, USA). In short, each second half of the muscle was immediately fixed with a glutaraldehyde solution $(6.25 \%$ glutaraldehyde, $0.1 \mathrm{M}$ sodium cacodylate buffer adjusted to $430 \mathrm{mosmol} \cdot \mathrm{L}^{-1}(16320$, EMS, Penn, PA, USA) and 1\% osmium tetroxide (0-5500, Sigma, St. Louis, MO, USA)). Stabilization of the fixatives was performed using $125 \mathrm{mM}$ sodium cacodylate buffer (C0250, Sigma). Samples were then embedded in an epoxy resin mixture (Polarbed 812 Resin, A22161/6, Bio $\mathrm{Rad})$ and subsequently polymerized at $60^{\circ} \mathrm{C}$. Several slices were obtained by systematically inclining the holder by $2^{\circ}$, and stained with $0.1 \%$ toluidine blue. As suggested by Poole et al. [28], optimal longitudinal sections were identified when a change of the sectioning angle in either direction resulted in a higher sarcomere length. Subsequently, 150-nm thin sections were obtained using a diamond-edged knife (Diatome, Biel, Switzerland) in an ultramicrotome (Ultracut E, Reichert-Jung, Vienna, 
Austria). These sections were stained using uranyl acetate-lead citrate. Micrographs were taken from 32 randomly selected fields at constant calibrated magnifications of $1,900 \times$ and $7,100 \times(16$ pictures each $)$, in a transmission electron microscope (Philips 301, Eindhoven, The Netherlands) with an accelerating voltage of $60 \mathrm{kV}$.

The structural analysis was performed on the micrographs using the above-mentioned semiautomatic system. The length $\left(L_{\mathrm{sar}}\right)$ and contraction ratio $(C \mathrm{R})$ of the sarcomeres, as well as the number $\left(\mathrm{n}_{\text {mit }}\right)$ and size of mitochondria, and the glycogen stores were evaluated in a double-blind manner. $L_{\mathrm{sar}}$ was defined as the distance between two consecutive $\mathrm{Z}$ discs, and was obtained from the mean value of all sarcomeres present in 16 fields at $1,900 \times$. An index $(C R)$ for assessing the degree of the contraction artifact was defined. Since $L_{\text {sar }}$ decreases during muscle contraction whereas the length of the A band remains constant [30], $C \mathrm{R}$ was calculated from the ratio between these two variables $\left(C \mathrm{R}=\mathrm{A}\right.$ band $\left./ L_{\mathrm{sar}}\right)$. This value was calculated for each sarcomere included in the analysis (3,000 in each individual). The $\mathrm{n}_{\text {mit }}$ was defined as the number of mitochondrial transections $(\mathrm{mt})$ present in the $7,100 \times$ fields, and was normalized to the micrographed area. The size of these organelles was assessed through their least diameter $\left(L D_{\text {mit }}\right.$, perimeter $\left(P_{\text {mit }}\right)$ and surface $\left(A_{\text {mit }}\right)$. To make pictures representative of any potential increase in size and/or number of mitochondrial clusters and to also take into account the more dispersed interfibrillary mitochondrial compartment, whole muscle fibre fields occupied the micrographs. This included both the subsarcolemmal space and wide areas of intermyofibrillar sarcoplasm. Finally, to assess glycogen stores, the cell area corresponding to aggregates of glycogen particles
$\left(A_{\text {gly }}\right)$ was measured and normalized to the whole area micrographed at $7,100 \times$.

\section{Statistical analysis}

Data are presented as mean \pm SD. Each variable was tested for normal distribution using the Kolmogorov-Smirnov test. Comparisons between groups were performed using the Mann-Whitney U-tests. Spearman's coefficient was obtained to assess correlation, and a linear regression analysis was used where appropriate. A p-value $\leq 0.05$ was considered significant.

\section{Results}

\section{Pulmonary and respiratory muscle functions}

Individual and mean functional values for the two groups are shown in table 1 . Eleven subjects showed mild to severe COPD, and twelve had air trapping (RV/TLC $>37 \%$, this included three subjects with normal spirometry). Arterial blood gases were normal except in four COPD patients who displayed light to moderate hypoxaemia. Variables expressing the strength of respiratory muscles (i.e. maximal inspiratory pressure (MIP) 106 \pm $40 \%$ reference; and $P$ di, $\max 95 \pm 31 \mathrm{cmH}_{2} \mathrm{O}$ ) were normal, and those related to their functional reserve $(P \mathrm{di} / P \mathrm{di}$,max $0.13 \pm 0.07$; and $T t$ di $0.05 \pm 0.03$ ) were far from the fatigue limits.

Table 1. - Main anthropometric, functional and structural characteristics of the patients

\begin{tabular}{|c|c|c|c|c|c|c|c|c|c|c|}
\hline $\begin{array}{l}\text { Patient } \\
\text { No. }\end{array}$ & $\begin{array}{l}\text { Age } \\
\text { yrs }\end{array}$ & $\begin{array}{c}\mathrm{BMI} \\
\mathrm{kg} \cdot \mathrm{m}^{-2}\end{array}$ & $\begin{array}{c}\mathrm{FEV}_{1 / \mathrm{FVC}} \\
\%\end{array}$ & $\begin{array}{l}\text { FEV1 } \\
\% \text { ref }^{-1}\end{array}$ & $\begin{array}{l}\text { FRC } \\
\% \text { ref }\end{array}$ & $\begin{array}{c}\mathrm{RV} / \mathrm{TLC} \\
\%\end{array}$ & $\begin{array}{c}\mathrm{Pa}_{\mathrm{a}, \mathrm{O}_{2}} \\
\mathrm{mmHg}\end{array}$ & $\begin{array}{c}\text { PI,max } \\
\text { \%ref }\end{array}$ & $\begin{array}{c}\mathrm{n}_{\mathrm{mit}} \\
\mathrm{mt} \cdot \mu \mathrm{m}^{-2}\end{array}$ & $\begin{array}{l}L_{\mathrm{sar}} \\
\mu \mathrm{m}\end{array}$ \\
\hline \multicolumn{11}{|c|}{ COPD patients } \\
\hline 1 & 69 & 25 & 45 & 44 & 170 & 61 & 98 & 38 & 0.82 & 2.16 \\
\hline 2 & 47 & 27 & 54 & 46 & 126 & 37 & 88 & 100 & 0.91 & 2.16 \\
\hline 3 & 68 & 24 & 43 & 53 & NA & NA & 87 & 67 & 0.52 & 2.38 \\
\hline 4 & 53 & 25 & 61 & 55 & 126 & 58 & 75 & 90 & 0.70 & 2.10 \\
\hline 5 & 62 & 25 & 68 & 62 & 115 & 39 & 89 & 111 & 0.53 & 1.90 \\
\hline 6 & 67 & 27 & 63 & 62 & 106 & 51 & 80 & 121 & 0.58 & 2.11 \\
\hline 7 & 46 & 20 & 57 & 64 & 100 & 32 & 100 & 96 & 0.43 & 2.14 \\
\hline 8 & 46 & 29 & 67 & 67 & 109 & 39 & 80 & 172 & 0.47 & 2.05 \\
\hline 9 & 64 & 29 & 67 & 67 & 130 & 46 & 62 & 153 & 0.47 & 2.29 \\
\hline 10 & 53 & 20 & 66 & 67 & 162 & 56 & 68 & 37 & 0.64 & 1.91 \\
\hline 11 & 70 & 24 & 68 & 71 & 206 & 65 & 79 & 44 & 0.74 & 1.84 \\
\hline Mean \pm SD & $59 \pm 10$ & $25 \pm 4$ & $60 \pm 9$ & $60 \pm 9$ & $135 \pm 34$ & $48 \pm 11$ & $82 \pm 12$ & $94 \pm 45$ & $0.62 \pm 0.16$ & $2.09 \pm 0.16$ \\
\hline \multicolumn{11}{|c|}{ Non-COPD patients } \\
\hline 12 & 46 & 22 & 71 & 80 & 109 & 31 & 87 & 124 & 0.33 & 2.27 \\
\hline 13 & 51 & 27 & 73 & 80 & 102 & 37 & 84 & 156 & 0.43 & 2.37 \\
\hline 14 & 66 & 28 & 76 & 81 & NA & NA & NA & 156 & 0.28 & 1.96 \\
\hline 15 & 69 & 23 & 72 & 85 & 128 & 44 & 95 & 109 & 0.83 & 2.13 \\
\hline 16 & 63 & 23 & 76 & 88 & 88 & 38 & 100 & 144 & 0.44 & 1.94 \\
\hline 17 & 59 & 24 & 71 & 89 & 102 & 33 & 88 & 95 & 0.51 & 2.37 \\
\hline 18 & 64 & 22 & 71 & 96 & 101 & 29 & 95 & 128 & 0.49 & 2.21 \\
\hline 19 & 68 & 29 & 79 & 96 & 88 & 28 & 91 & 72 & 0.48 & 2.50 \\
\hline 20 & 71 & 23 & 72 & 99 & 87 & 29 & 79 & 107 & 0.35 & 2.12 \\
\hline $\operatorname{Mean} \pm$ SD & $62 \pm 8$ & $25 \pm 2$ & $74 \pm 3$ & $88 \pm 7$ & $100 \pm 14$ & $33 \pm 6$ & $90 \pm 7$ & $121 \pm 28$ & $0.46 \pm 0.16$ & $2.21 \pm 0.19$ \\
\hline
\end{tabular}




\section{Nutritional status}

This was strictly normal in all patients and no relationships were found between nutritional and structural items.

\section{Structural analysis of the diaphragm}

Light microscopy. In all samples, both types of fibres were distributed in the typical mosaic pattern. Type I accounted for $52 \pm 3 \%$ of the fibres, and the size was similar for type I and type II (diameter, $58 \pm 12$ versus $61 \pm 14$ $\mu \mathrm{m}$, respectively).

Electron microscopy. Mitochondria were found to be mainly distributed in the subsarcolemmal compartment. The $\mathrm{n}_{\text {mit }}$ was $0.55 \pm 0.17 \mathrm{mt} \cdot \mu \mathrm{m}^{-2}$, with an $\mathrm{LD}_{\text {mit }}$ of $496 \pm$ $85 \mathrm{~nm}, P_{\text {mit }}$ of $2.47 \pm 0.36 \mu \mathrm{m}$ and $\mathrm{A}_{\text {mit }}$ of $7.18 \pm 1.85$ $\mu \mathrm{m}^{-2}$. The index of the sample contraction was very homogeneous $(72.4 \pm 2.8)$ for the entire population, with $L_{\text {sar }}$ showing a value of $2.15 \pm 0.18 \mu \mathrm{m}$. With respect to glycogen aggregates, these always appeared in the monoparticular form, with $A_{\text {gly }}$ representing $8.7 \pm 3.6 \%$ of the cellular area.

\section{Respiratory function and structure of the diaphragm}

Interestingly, patients suffering from a COPD showed a higher mitochondrial density than subjects without airways obstruction $\left(0.62 \pm 0.16\right.$ versus $0.46 \pm 0.16 \mathrm{mt} \cdot \mu \mathrm{m}^{-2}$, $\mathrm{p}<0.05)$ (fig. 1). Furthermore, an inverse correlation was found between the degree of airways obstruction (represented by FEV1) and nmit ( $\mathrm{r}=-0.555, \mathrm{p}=0.01$ ) (fig. 2). In addition, clusters of mitochondria were frequently found in COPD patients (fig. 3) and, in three of them, mitochondrial paracrystalline inclusions were observed (fig. 4). Variables reflecting the size of mitochondrial transections (i.e. $L D_{\text {mit }}, P_{\text {mit }}$ and $A_{\text {mit }}$ ) did not correlate with any of the functional variables. On the other hand, although the $L_{\mathrm{sar}}$ was slightly shorter in COPD $(2.09 \pm 0.16$ versus $2.21 \pm 0.19)$, this difference did not reach statistical significance $(\mathrm{p}=0.1)$. However, when all individuals with air trapping (RV/TLC $>37 \%)$ were grouped (most of the COPD patients plus three subjects with normal spirometric values), a higher $\mathrm{n}_{\mathrm{mit}}$ and shorter sarcomeres were observed, in contrast to subjects without this functional abnormality $\left(0.63 \pm 0.17\right.$ versus $0.43 \pm 0.07 \mathrm{mt} \cdot \mu \mathrm{m}^{-2}, \mathrm{p}<$ 0.05 ; and $2.08 \pm 0.16$ versus $2.27 \pm 0.15 \mu \mathrm{m}, \mathrm{p}<0.05$, respectively) (fig. 1). In the same way, $L_{\text {sar }}$ was found to inversely correlate with the severity of air trapping (with $\mathrm{RV}, \mathrm{r}=-0.548, \mathrm{p}=0.02$; with RV/TLC, $\mathrm{r}=-0.526, \mathrm{p}<0.05)$ and pulmonary hyperinflation (with $\mathrm{FRC}, \mathrm{r}=-0.483$, $\mathrm{p}<0.05$ ) (fig. 5). A similar but direct relationship was obtained between static lung volumes and $\mathrm{n}_{\text {mit }}$ (with $\mathrm{RV}$, $\mathrm{r}=0.589, \mathrm{p}=0.01$; with RV/TLC, $\mathrm{r}=0.631$, $\mathrm{p}<0.01$; with FRC, $r=0.657, p<0.01)$. It is worth noting that $C R$ not only showed a narrow range in this series, but was similar for different groups (COPD versus subjects with normal spirometry, $72 \pm 3$ versus $73 \pm 2$, respectively; individuals with and without air trapping, $73 \pm 3$ versus $72 \pm 2$, respectively), and did not correlate with $\mathrm{n}_{\text {mit }}$. Finally, no differences were observed for glycogen stores or the size
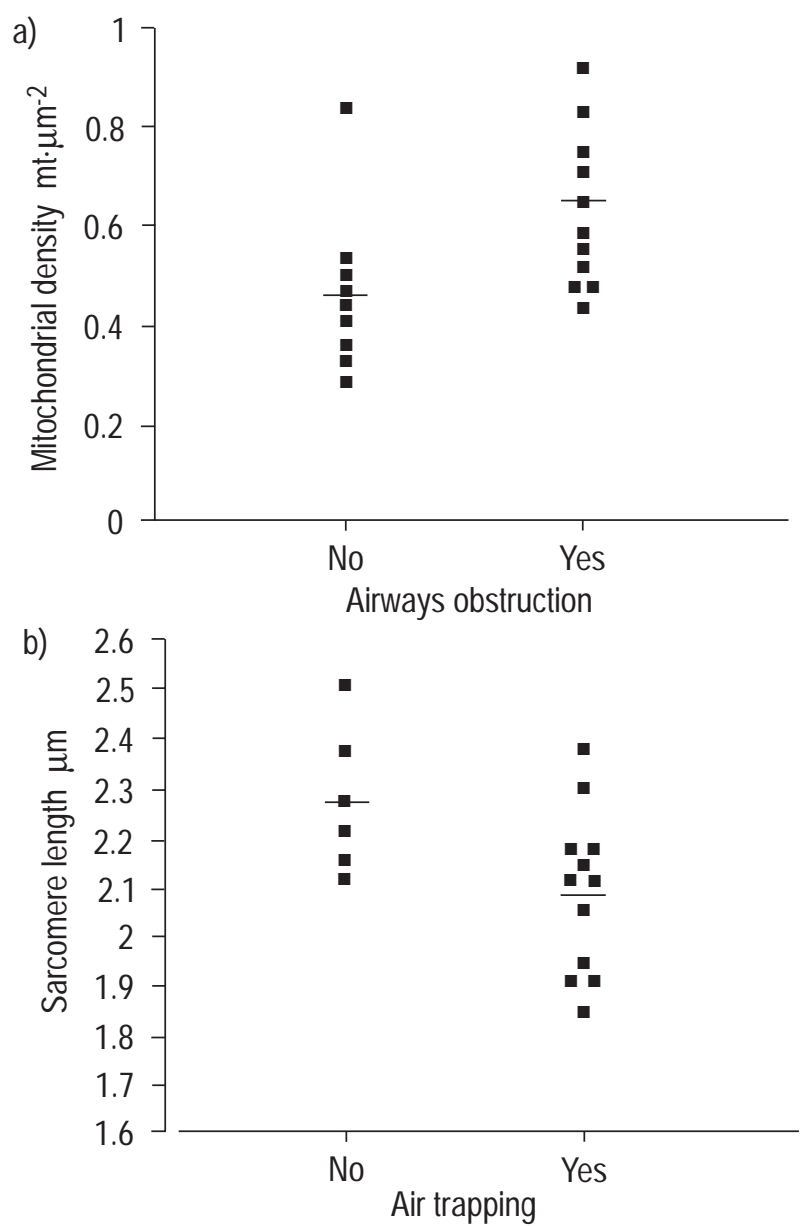

Fig. 1. - Differences in a) diaphragmatic mitochondrial density $\left(\mathrm{n}_{\text {mit }}\right)$ with reference to airways obstruction, and $b$ ) in the length of sarcomeres $\left(L_{\mathrm{sar}}\right)$ with reference to air trapping $(\mathrm{p}<0.05$, both). $\mathrm{mt}$ : mitochondrial transections.

of the fibres between COPD and controls $\left(A_{\text {gly }} 9.2 \pm 3.7\right.$ versus $8.1 \pm 3.6 \%$; diameter of type I fibres, $60 \pm 14$ versus $58 \pm 11 \mu$; diameter of type II, $58 \pm 16$ versus $62 \pm 14 \mu$ ).

Respiratory muscle function and structure of the diaphragm

An inverse correlation was found between $\% P I$, max and $\mathrm{n}_{\text {mit }}(\mathrm{r}=-0.547, \mathrm{p}=0.01)$ (fig. 2). The relationship did not reach statistical significance for $P$ di,max. No correlations were observed between $L_{\text {sar }}$ and respiratory muscle function.

\section{Discussion}

The main finding of this study is the close association observed between lung function and the subcellular structure of the human diaphragm. Specifically, structural differences in the length of sarcomeres and mitochondrial content were observed in COPD patients, when these were compared with the control group. Furthermore, some of these changes appeared to be proportional to the degree of either airways obstruction, pulmonary hyperinflation or air 

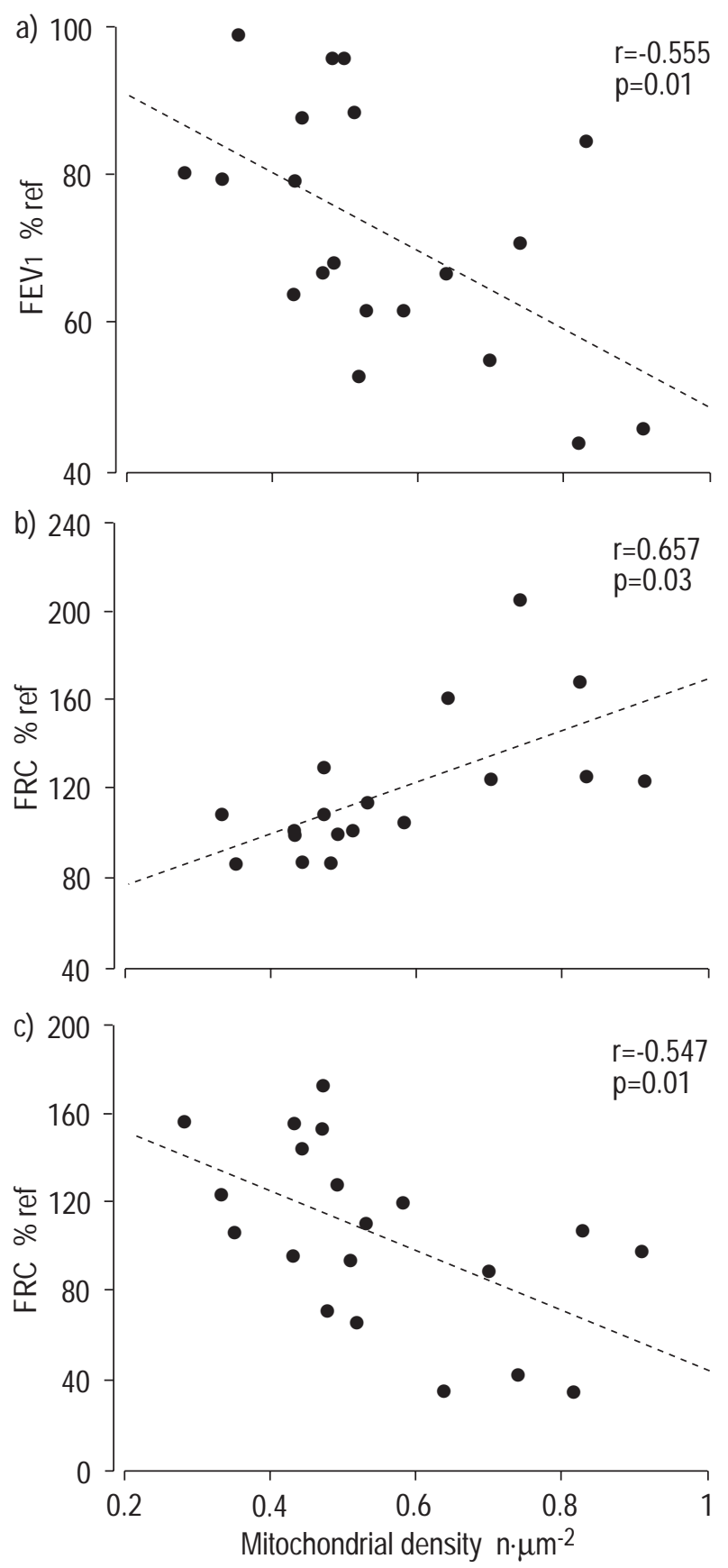

Fig. 2. - Plot of mitochondrial density $\left(\mathrm{n}_{\mathrm{mit}}\right)$ with the severity of airways obstruction in a) forced expiratory volume in one second (FEV1), b) functional residual capacity (FRC) and c) maximal inspiratory pressure $(P \mathrm{I}, \max )$. ref: reference. - - - - : regression line.

trapping. These findings could be considered representative of an adaptive trend of the muscle against chronic ventilatory loading. The latter is strongly suggested by the association also observed between the structural changes and the strength of respiratory muscles. As far as the authors are aware, this is the first study evaluating the ultrastructure of the human diaphragm and its relationships with both lung and respiratory muscle functions.

Skeletal peripheral muscles have been shown to be very malleable in their adaptive response to different forms of chronic use and disuse [31]. The multitude of observed

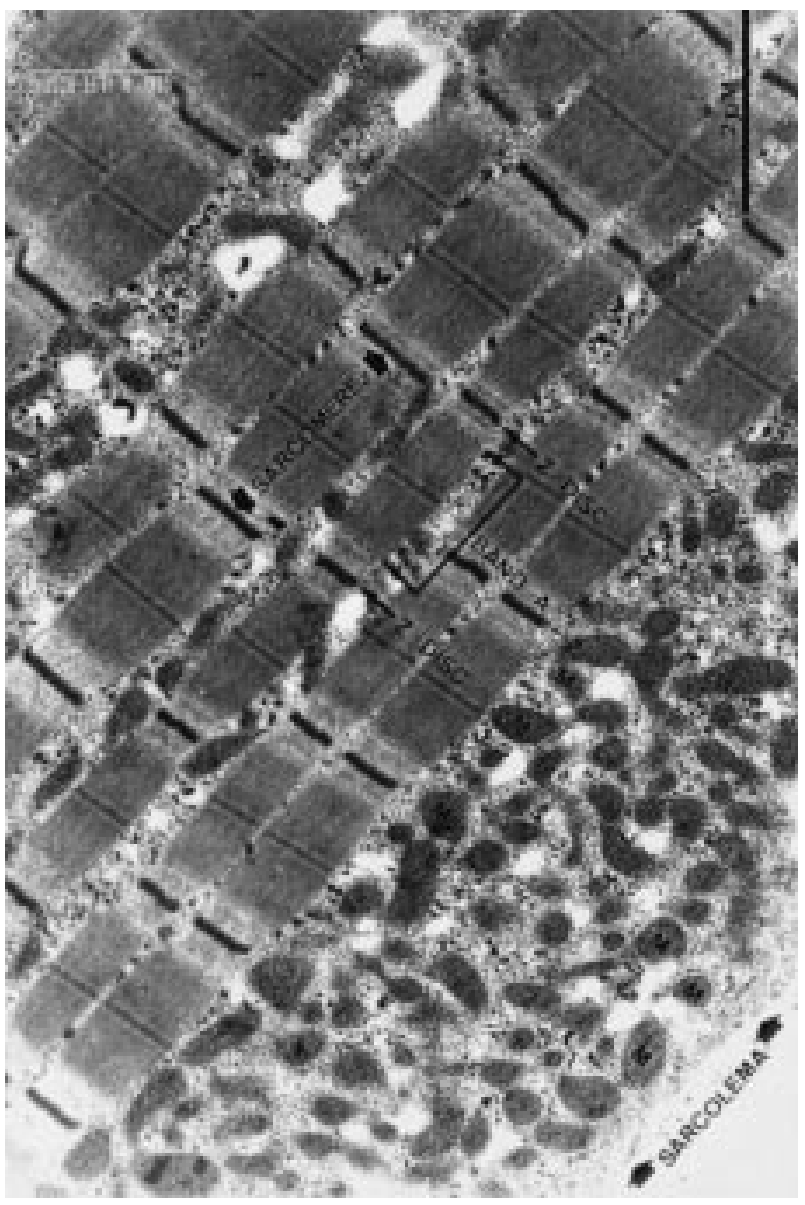

Fig. 3. - Micrograph showing subsarcolemmal clustering of mitochondria in a diaphragm cell from a chronic obstructive pulmonary disease patient (forced expiratory volume in one second, $46 \%$ predicted). Variables included in the evaluation of the contraction ratio $(C \mathrm{R})$ of the sarcomeres (A band and length of sarcomeres $\left(L_{\text {sar }}\right)$ ) are also shown. (Internal scale bar $=2 \mu \mathrm{M}$.)

phenotypic changes include modifications in mitochondrial content, oxidative capacity, the size and relative frequency of different fibre types, and the length and number of sarcomeres. Descriptions of these adaptive processes in skeletal limb muscles are plentiful. However, relatively few studies have investigated structural remodelling in respiratory muscles. These studies have been focused mainly on their cellular structure (i.e. the size and proportion of different fibre types) [9, 17-19]. As a consequence, little is known about the subcellular structure of the diaphragm in experimental models of respiratory diseases, and almost nothing in COPD patients. This lack of data is probably due to technical and ethical limitations in obtaining valid samples of the muscle and at the same time availing of a functional evaluation. Until recently, current models were necropsies or biopsies during a thoracotomy. In the former model, functional assessment is either absent or too far from sampling. In addition, many associated phenomena could interfere with the structural analysis. With reference to sampling during thoracotomy, the procedure employed in the present study, advantages and limitations will be specifically discussed below. Interestingly, in recent years, two new models have been described for obtaining diaphragmatic samples "in vivo" 


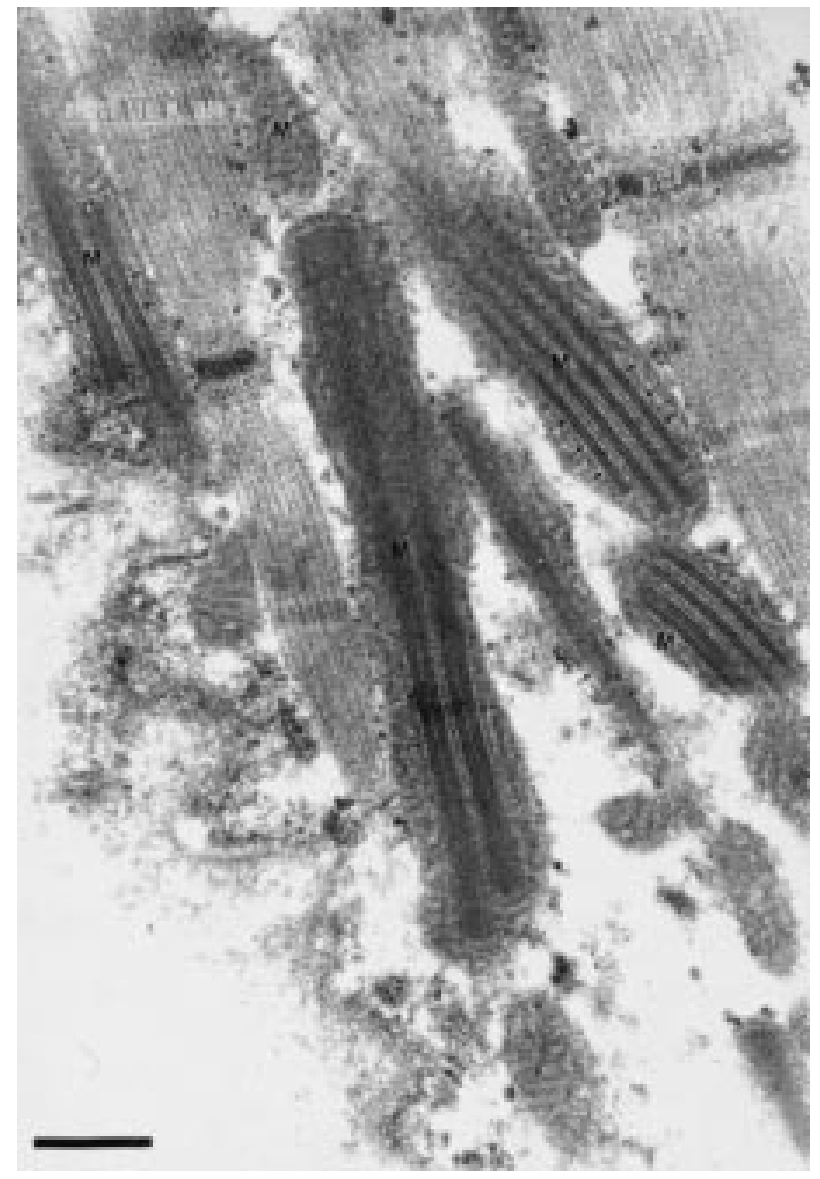

Fig. 4. - Micrograph showing mitochondrial (M) paracrystalline inclusions (arrows) in the diaphragm of the same chronic obstructive pulmonary disease patient as in figure 3 . (Internal scale bar $=2 \mu \mathrm{m}$.)

namely from subjects submitted to upper laparotomy [32] and COPD patients undergoing surgical reduction of lung volume [9].

\section{Sarcomere length}

This study shows that air trapping is closely associated with shorter sarcomeres in the diaphragm. Furthermore, the greater the lung volumes, the shorter the length of sarcomeres. These results confirm those observed in previous experimental models. Hamsters with induced emphysema were shown to have a reduction in both the number and length of their diaphragmatic sarcomeres [16]. This structural change was associated with the preservation of the capacity to generate tension, as was the case in the patients of the present study. The hypothesis is that sarcomere shortening probably results in a partial reversion of the displacement of the diaphragmatic length-tension curve due to pulmonary hyperinflation [33]. This would also explain the findings of SimiLowsKy et al. [7] demonstrating that patients with COPD develop even higher diaphragmatic strength than normal subjects at equivalent lung volumes.

Using an inverse train of thought, if the diaphragm preserves its intrinsic properties for generating pressure, a type of structural adaptation should be present: either an


Fig. 5. - Plots of length of sarcomeres $\left(L_{\mathrm{sar}}\right)$ with static lung volumes for a) residual volume (RV), b) RV/total lung capacity (TLC), and c) functional residual capacity (FRC). ref: reference. - - - - : regression.

increase in the size of the fibres, a change in their relative proportions or a decrease in the length of sarcomeres are the more likely hypotheses. This study demonstrates that the shortening in sarcomeres really does occur in COPD patients. In addition (and as previous authors have described $[17,18])$, the data in the present study discard the former hypothesis: fibres were, in fact, similar in COPD and controls. With reference to the second possibility (a change in the proportion of fibres), a recent paper by LEVINE et al. [9] has demonstrated a switch to slow type fibres and the homonimous myosin heavy chain isoform in severe COPD patients [7]. 
Other authors have failed to find similar relationships between the length of the muscle filaments and functional behaviour of the diaphragm [28], although this is probably owing to the relatively short course of the disease in current experimental models. In other words, the subacute emphysema generated in animals cannot entirely mimic the slow and progressive development of a COPD in humans. This would be specially notable in consequences of chronic mechanical loading on the structural adaptive changes of respiratory muscles and thus further emphasize the relevance of this study.

One possible criticism is a potential artifact in sarcomere length due to muscle contraction. However, this seems unlikely, since muscle bundles were immediately fixed after surgery. In addition, the small dispersion of the variable assessing the degree of contraction reveals that, if present, this factor was similar for all the different samples.

\section{Mitochondria}

In this study the number of mitochondrial transections in the diaphragm has been shown to be higher in COPD patients. Moreover, mitochondrial density was associated with the severity of both airway obstruction and pulmonary hyperinflation. Although the design of the study does not make it possible to assign a cause-effect relationship, it is well established that the number of mitochondria increases in other muscles submitted to overloads [31]. Since airflow obstruction imposes a persistent mechanical load on the inspiratory muscles, changes in the concentration of energetic organelles should also be expected here [34, 35].

Either an actual increase in mitochondria or a change in the shape of these organelles could explain the high value of mitochondrial transections observed in these COPD patients. However, the latter seems less probable, since this would implicate a highly convoluted reticulum along an appreciable length of the myocyte. Another possible criticism is the potential bias in the evaluation of mitochondria due to the involuntary selection of a specific fibre type. However, although no standardized method exists which allows us to differentiate the fibre subtypes during electron microscopy analysis, this bias is unlikely: populations of slow and fast-twitch fibres were similar, there were no clusters of a specific subtype, and fields were randomly selected. In addition, as LEWIS et al. [11] have demonstrated, the metabolic adaptation of the diaphragm is nonspecific for a determined subtype of fibres.

An interesting point for discussion is whether or not changes in the mitochondrial density have functional relevance. In fact, trained limb muscles increase the content of these organelles, using carbohydrates sparingly and displaying greater levels of $\beta$-oxidation enzymes [36]. This results in a smaller disruption of homeostasis during exercise [30]. The present study demonstrated similar structural changes in the diaphragm of COPD patients. If their functional significance is similar, as suggested by the increased oxidative capacity reported by HugHes et al. [37], the muscle would be allowed to work for longer before becoming fatigued [31]. Once again, the strikingly direct relationship observed between the mitochondrial density and the strength of inspiratory muscles in these patients can be viewed as the functional expression of their structural adaptation.
A short comment should be made about potential regulators of the number of mitochondria in the diaphragm of COPD patients. Although no specific studies have been carried out, some of the factors that could be present in this condition (such as muscle hypoxia or depletion of high energy phosphates) can induce changes in the mitochondrial content in limb muscles [31].

Finally, paracrystalline inclusions observed in some of these COPD patients, and previously described by this group [38], probably reflect the metabolic mismatching present in the mitochondria of this population [39].

\section{Limitations of the model}

Thoracotomy has been used in this and almost all previous studies concerning the structure of the diaphragm $[17-19,37]$. This procedure allows us to obtain samples of the diaphragm in vivo, making a close functional and nutritional evaluation possible, and avoiding cellular phenomena related to death. However, it does have its limitations: many severe COPD patients cannot be submitted to this surgery and a possible bias can exist owing to the presence of a malignancy. However, the close selection of these patients reasonably excludes the latter objection: nutritional parameters were normal, the neoplasm was small and limited to the thorax and there were no signs of associated paraneoplastic syndromes.

In conclusion, the present study demonstrates shorter sarcomeres and a higher mitochondrial content in the diaphragm of patients with chronic airways obstruction and/or increased lung volumes. These findings support the notion that respiratory muscles undergo structural remodelling and adaptation in chronic obstructive pulmonary disease patients.

Acknowledgements. The authors thank A.E. Grassino, J.M. Antó and D. Maldonado for their kind review of the article and invaluable suggestions; J. Sauleda for the collection of some of the samples; N. Soler, A. Roig and P. García for their excellent technical assistance; and to J.A. Salazar for his editing.

\section{References}

1. Anonymous. ATS standards for the diagnosis and care of patients with chronic obstructive pulmonary disease (COPD). Am Rev Respir Dis 1987; 136: 225-231.

2. Higgings MW, Thom TJ. Incidence, prevalence, and mortality: intra- and intercountry differences. In: Hensley MJ, Saunders NA, eds. Clinical Epidemiology of COPD. New York, Marcel Dekker, 1989; pp. 72-75.

3. Thom TJ. International comparisons in COPD mortality. Am Rev Respir Dis 1989; 140: s27.

4. Derenne JP, Macklem PT, Roussos C. The respiratory muscles: mechanics, control and pathophysiology. Part I. Am Rev Respir Dis 1978; 118: 115-133.

5. Derenne JP, Macklem PT, Roussos C. The respiratory muscles: mechanics, control and pathophysiology. Part II. Am Rev Respir Dis 1978; 118: 373-390.

6. Derenne JP, Macklem PT, Roussos C. The respiratory muscles: mechanics, control and pathophysiology. Part II. Am Rev Respir Dis 1978; 118: 581-601.

7. Similowsky T, Yan S, Gauthier A, Macklem PT, Bellemare F. Contractile properties of the human diaphragm 
during chronic hyperinflation. $N$ Engl J Med 1991; 325: 917-923.

8. Tamaoki J. Effects of elastase-induced emphysema on histochemical properties of guinea pig diaphragm. Respiration 1988; 54: 16-24.

9. Levine S, Kaiser L, Leferovich J, Tikunov B. Cellular adaptations in the diaphragm in chronic obstructive pulmonary disease. N Engl J Med 1997; 337: 1799-1806.

10. Farkas GA, Roussos C. Histochemical and biochemical correlates of ventilatory muscle fatigue in emphysematous hamsters. J Clin Invest 1984; 74: 1214-1220.

11. Lewis MI, Zhan WZ, Sleek GC. Adaptations of the diaphragm in emphysema. $J$ Appl Physiol 1992; 72: 934943.

12. Supinsky GS, Kelsen SG. Effect of elastase-induced emphysema on the force generating ability of the diaphragm. J Clin Invest 1982; 70: 978-988.

13. Sauleda J, Gea J, Orozco-Levi M, et al. Structure and function relationships of the respiratory muscles. Eur Respir J 1998; 11: 906-911.

14. Keens TA, Chen V, Patel P, O'Brien P, Levison H, Ianuzzo $\mathrm{CD}$. Cellular adaptations of the ventilatory muscles to a chronic increased ventilatory load. J Appl Physiol 1978; 44: 905-908.

15. Akabas SR, Bazzy AR, DiMauro S, Haddad GG. Metabolic and functional adaptation of the diaphragm to training with resistive loads. J Appl Physiol 1989; 66: 529-535

16. Farkas GA, Roussos C. Adaptability of the hamster diaphragm to exercise and/or emphysema. J Appl Physiol 1982; 53: 1263-1272.

17. Hards JM, Reid WD, Pardy RL, Paré PB. Respiratory muscle fiber morphometry: correlation with pulmonary function and nutrition. Chest 1990; 97: 1037-1044.

18. Sanchez J, Derenne JP, Debesse B, Riquet M, Monod H. Typology of the respiratory muscles in normal men and in patients with moderate chronic obstructive pulmonary diseases. Bull Eur Physiopathol Respir 1982; 18: 901914.

19. Campbell JA, Hughes RL, Sahgal V, Frederiksen J, Shields TW. Alterations in intercostal muscle morphology and biochemistry in patients with obstructive lung disease. Am Rev Respir Dis 1980; 122: 679-686.

20. Roca J, Sanchís J, Agustí-Vidal A, Rodriguez-Roisin R Spirometric reference values for a Mediterranean population. Bull Eur Physiopathol Respir 1986; 22: 217-224.

21. Roca J, Rodríguez-Roisin R, Cobo E, Burgos F, Pérez J, Clausen JL. Single breath carbon monoxide diffusing capacity (DLCO) prediction equations for a Mediterranean population. Am Rev Respir Dis 1990; 141: 10261032.

22. Laporta D, Grassino A. Assessment of transdiaphragmatic pressure in humans. J Appl Physiol 1985; 58: 14691476.

23. Aran X, Gea J, Guiu R, Aguar MC, Sauleda J, Broquetas JM. Comparison between three different maneouvres for achieving maximal transdiaphragmatic pressures. Arch Bronconeumol 1992; 28: 112-115.

24. Bellemare F, Grassino A. Effect of pressure and timing of contraction on human diaphragm fatigue. J Appl Physiol 1982; 68: 2296-2304.

25. Wilson SH, Cooke NT, Edwards RHT. Predicted normal values for maximal inspiratory pressure in caucasian adults and children. Thorax 1984; 39: 535-538.

26. Feliffe DB. The assessment of the nutritional status in the community. Geneve, WHO, 1996; p. 53.

27. Dubowitz V, Brooke MH. Muscle biopsy: a modern approach. In: Dubowitz V, Brooke MH, eds. Major Problems in Neurology. Saunders, London, 1973; pp. 74-85.

28. Poole DC, Lieber RL, Mathieu-Costello O. Myosin and actin filaments lengths in diaphragms from emphysematous hamsters. J Appl Physiol 1994; 76: 1220-1225.

29. Brooke MH, Engels WK. The histographic analysis of human muscle biopsies with regard to fibre types. 1 . Adult male and female. Neurology 1969; 19: 221-233.

30. Gordon AM, Huxley AF, Julian FJ. Tension development in highly stretched vertebrate muscle fibers. $J$ Physiol 1966; 184: 143-169.

31. Booth FW, Thomason DB. Molecular and cellular adaptation of muscle in response to exercise: perspectives of various models. Physiol Rev 1991; 71: 541-585.

32. Pastó M, Minguella J, Gea J, Gallego F, Félez MA, Broquetas JM. A new surgical model that allows structural studies of the diaphragm even in very severe COPD patients. Eur Respir J 1997; 10: Suppl. 25, 167s.

33. Smith J, Bellemare F. Effect of lung volume on in vivo contraction characteristics of human diaphragm. J Appl Physiol 1987; 62: 1893-1900.

34. Gollnik PD, Armstrong RB, Saltin B, Saubert CW, Sembrowich WL, Shepherd RE. Effect of training on enzyme activity and fiber composition of human skeletal muscle. J Appl Physiol 1979; 34: 107-111.

35. Takahashi M, Hood DA. Chronic stimulation-induced changes in mitochondria and performance in rat skeletal muscle. J Appl Physiol 1993; 74: 934-941.

36. Molé PA, Oscai LB, Hollosky O. Adaptation of muscle to exercise. Increase in levels of palmityl CoA synthetase, carnitine palmitytransferase, and palmitylCoA dehydrogenase, and in the capacity to oxidize fatty acids. $J$ Clin Invest 1971; 50: 2322-2330.

37. Hughes RL, Katz H, Sahgal V, Campbell JA, Harz R, Shields TW. Fiber size and energy metabolites in five separate muscles from patients with chronic obstructive lung Disease. Respiration 1983; 44: 321-323.

38. Lloreta J, Orozco-Levi M, Gea J, Corominas JM, Serrano S. Selective diaphragmatic abnormalities in a patient with marked airflow obstruction. Ultrastruct Pathol 1996; 20: 67-71.

39. Sauleda J, García-Palmer F, Wiesner RJ, et al. Cytochrome oxidase activity and mitochondrial gene expression in skeletal muscle of patients with COPD. Am J Respir Crit Care Med 1998; 157: 1413-1417. 